OPEN ACCESS

Edited by:

Soren K. Rasmussen, University of Copenhagen, Denmark

Reviewed by:

Fernando Carols Gómez-Merino, Colegio de Postgraduados, Mexico Libia Iris Trejo-Téllez,

Colegio de Postgraduados, Mexico

${ }^{*}$ Correspondence: Jinquan $L$

lijinquan@scau.edu.cn

Specialty section:

This article was submitted to Crop Science and Horticulture,

a section of the journal

Frontiers in Plant Science

Received: 30 January 2016 Accepted: 05 September 2016 Published: 04 October 2016

Citation:

Zhang $P$, Zhong $K$, Tong $H$,

Shahid MQ and Li J (2016) Association Mapping for Aluminum Tolerance in a Core Collection of Rice Landraces. Front. Plant Sci. 7:1415. doi: $10.3389 /$ fpls.2016.01415

\section{Association Mapping for Aluminum Tolerance in a Core Collection of Rice Landraces}

\author{
Peng Zhang ${ }^{1,2}$, Kaizhen Zhong ${ }^{1}$, Hanhua Tong ${ }^{1}$, Muhammad Qasim Shahid ${ }^{2}$ and \\ Jinquan $L i^{2,3 *}$
}

${ }^{1}$ State Key Laboratory of Rice Biology, China National Rice Research Institute, Hangzhou, China, ${ }^{2}$ State Key Laboratory for Conservation and Utilization of Subtropical Agro-Bioresources, South China Agricultural University, Guangzhou, China,

${ }^{3}$ Department of Plant Breeding and Genetics, Max Planck Institute for Plant Breeding Research, Cologne, Germany

Trivalent aluminum $\left(\mathrm{Al}^{3+}\right)$ has drastic effect on the rice production in acidic soils. Elite genes for aluminum (Al) tolerance might exist in rice landraces. Therefore, the purpose of this research is to mine the elite genes within rice landraces. Association mapping for Al tolerance traits [i.e., relative root elongation (RRE)] was performed by using a core collection of 150 accessions of rice landraces (i.e., Ting's rice core collection). Our results showed that the Ting's rice core collection possessed a wide-range of phenotypic variation for Al tolerance, and the index of Al tolerance (RRE) was ranged from 0.22 to 0.89 . Moreover, the groups with different origins and compositions of indica and japonica rice showed different degrees of tolerance to varying levels of Al. These rice landraces were further screened with 274 simple sequence repeat markers, and association mapping was performed using a mixed linear model approach. The mapping results showed that a total of 23 significant $(P<0.05)$ trait-marker associations were detected for $\mathrm{Al}$ tolerance. Of these, three associations (13\%) were identical to the quantitative trait loci reported previously, and other 20 associations were reported for the first time in this study. The proportion of phenotypic variance $\left(R^{2}\right)$ explained by 23 significant associations ranged from 5.03 to $20.03 \%$ for Al tolerance. We detected several elite alleles for Al tolerance based on multiple comparisons of allelic effects, which could be used to develop Al tolerant rice cultivars through marker-assisted breeding.

\footnotetext{
Keywords: Ting's core collection, rice aluminum tolerance, relative root elongation, association mapping, mixed linear model, allele effect
}

\section{INTRODUCTION}

Acidic soils occupy approximately $30 \%$ of the world's ice-free area, and over $50 \%$ of the world's arable land is acidic (Vonuexkull and Mutert, 1995; Kochian et al., 2004; Ryan et al., 2011). Aluminum ( $\mathrm{Al})$ is the most abundant metal in the earth's crust. $\mathrm{Al}$ is solubilized as trivalent $\mathrm{Al}$ $\left(\mathrm{Al}^{3+}\right)$ in acidic soils with $\mathrm{pH}$ values below 5.0. Al has been shown to be beneficial to some plant species including rice when supplied at low concentrations, and Al's benefits were summarized in

Abbreviations: $\mathrm{Al}^{3+}$, trivalent aluminum; GLM, general linear model; MLM, mixed linear model; PIC, polymorphism information content; QTL, quantitative trait locus; RRE, relative root elongation; SD, standard deviation; SSR, simple sequence repeat. 
a review of Pilon-Smits et al. (2009). Though beneficial at low level, $\mathrm{Al}^{3+}$ at high concentrations inhibits root growth, damages root systems, and causes significant reductions in crop yields (Liu et al., 2012). $\mathrm{Al}^{3+}$ is the major toxic cation encountered by plants on acidic soils (Delhaize et al., 2012b). Up to $60 \%$ of the acidic soils in the world occur in developing countries, where food production is affected by $\mathrm{Al}$ toxicity in acid land and always a major area of research for plant physiologists and breeders (Kochian et al., 2005; Delhaize et al., 2012a; Fujii et al., 2012; Xia et al., 2013; Caniato et al., 2014; Li et al., 2014). Therefore, identification of elite genes for $\mathrm{Al}$ tolerance is of paramount importance for plant growth and production in the world.

Rice (Oryza sativa L.) is the most Al tolerant crop among small grain cereals (Ma et al., 2002) and is one of the world's most important crops, supplying food for nearly half of the world's population, especially in Asia. About 13\% of global rice produced on acidic soils (Vonuexkull and Mutert, 1995). Therefore, improving Al tolerance of rice is highly valuable for rice production. In recent years, many scientists have studied genetic mechanism of Al tolerance in rice (Huang et al., 2009; Yamaji et al., 2009; Xia et al., 2010; Famoso et al., 2011; Li et al., 2014; Arenhart et al., 2016; Yokosho et al., 2016). Most of the rice researches were focused on $\mathrm{Al}$ tolerance at seedling stage, and reported some rice accessions or mutants which were tolerant or sensitive to $\mathrm{Al}$ by measuring relative root elongation (RRE). Furthermore, previous studies illuminated that there were two detoxification mechanisms under $\mathrm{Al}^{3+}$ threaten, i.e., exclusion of $\mathrm{Al}$ from root cells by producing and excreting chelating chemicals (Yokosho et al., 2011) and accumulation of $\mathrm{Al}$ and internal detoxification (Huang et al., 2009; Yamaji et al., 2009; Arenhart et al., 2013, 2014).

A number of quantitative trait loci (QTLs) for Al tolerance have been identified in rice by using different mapping populations (Nguyen et al., 2002; Ma and Furukawa, 2003; Mao et al., 2004; Xue et al., 2007; Famoso et al., 2011), and a few genes conferring $\mathrm{Al}$ tolerance have been identified (Huang et al., 2009, 2012; Yamaji et al., 2009; Yokosho et al., 2011; Chen et al., 2012; Xia et al., 2013; Li et al., 2014). However, QTL mapping was done by using conventional linkage mapping methods in the segregating populations derived from crossing between typical $\mathrm{Al}$ tolerant and sensitive rice varieties in the previous studies. The linkage mapping have major limitations, including only two alleles at any given locus can be studied in bi-parental crosses, high cost and poor mapping resolution (Flint-Garcia et al., 2003), whereas association mapping could overcome the limitations of linkage mapping (Kraakman et al., 2004) and enables researchers to use modern genetic technologies to exploit natural genetic diversity and identify elite genes in the genome (Zhu et al., 2008). However, as far as we know, association mapping by using a natural population was seldom performed in the previous studies on $\mathrm{Al}$ tolerance.

An appropriate population with maximized phenotypic variation is critical for the success of an association analysis (Yan et al., 2011). Rice landraces represent an intermediate stage in domestication between wild and elite cultivars (Londo et al., 2006), which possess high genetic diversity and many exotic genes, and thereby provide useful germplasm resources for rice breeding. Moreover, association mapping based on a core collection of rice landraces would help to attain as much phenotypic variation as possible. However, the knowledge about the association mapping in a core collection of rice landraces for the $\mathrm{Al}$ tolerance trait is rather limited. Though Famoso et al. (2011) have performed association mapping for $\mathrm{Al}$ tolerance by using 383 diverse rice accessions, they were not complete rice landraces. Moreover, these rice accessions were not from a complete core collection.

As one of the earliest rice collections in China, Ting's rice collection was collected by the researcher Ying Ting during 1920-1964 from all over China as well as from Korea, Japan, Philippines, Brazil, Indonesia, Australia, and Vietnam (Li and Zhang, 2012). The original collection comprises of 7128 rice landraces. In our previous studies, a core collection with 150 accessions was constructed from 2262 accessions out of 7128 based on a strategy of stepwise clustering and preferred sampling on adjusted Euclidean distances and weighted pair-group average method using integrated qualitative and quantitative traits (Li et al., 2011). Population structure and linkage disequilibrium (LD) level of the rice core collection had been examined in details (Zhang et al., 2011). A large number of accessions in Ting's core collection showed distinct Al tolerance. Moreover, the Ting's core collection has been used for association mapping of agronomic traits, and some of the mapping results with the core collection could be confirmed in other two mapping populations as well as being consistent with previous mapping results (Zhang et al., 2014). Therefore, the Ting's core collection could be an appropriate population for association mapping studies of $\mathrm{Al}$ tolerance.

In the present study, an association mapping for AL tolerance was carried out using the Ting's core collection of rice landraces with 274 simple sequence repeat (SSR) markers. The study aimed to (1) identify phenotypic variations for Al tolerance in the rice landraces of the core collection, (2) perform association mapping for $\mathrm{Al}$ tolerance using the core collection, and (3) identify potential alleles of the loci that showed significant traitmarker associations with $\mathrm{Al}$ tolerance. These information will be very useful for the rice breeders to enhance the resistance of elite cultivars against $\mathrm{Al}$.

\section{MATERIALS AND METHODS}

\section{Plant Material}

The Ting's core collection with 150 accessions of rice landraces (Li et al., 2011) was used in this study. The information for these accessions is shown in Supplementary Table S1. In addition, two Al tolerant varieties, i.e., Nipponbare and Xiangnuo 1 (Yang et al., 2007) as well as three Al sensitive varieties, i.e., Nante ( $\mathrm{Fu}$ et al., 2010), Xiangzhongxian 2 (Xu et al., 2004), and IR64 (Khatiwada et al., 1996) were selected to 
identify the most accurate concentration of $\mathrm{Al}$ toxicity in this study.

\section{Screening for Al Tolerance}

Uniform seeds of the two $\mathrm{Al}$ tolerant and three $\mathrm{Al}$ sensitive varieties were surface sterilized in $1 \% \mathrm{H}_{2} \mathrm{O}_{2}$ for $30 \mathrm{~min}$, and then washed with deionized water for several times. After this, rice seeds were soaked to germinate in deionized water overnight at $30^{\circ} \mathrm{C}$ for 2 days in dark. The seedlings were transferred to a plastic net floating on a $0.5 \mathrm{mmol} \mathrm{l}^{-1} \mathrm{CaCl}_{2}(\mathrm{pH}=4.0)$ solution in a 1.5-l plastic container, and seedlings were grown at $28^{\circ} \mathrm{C}$. The solution was renewed daily and no other nutrient solution was provided. Previous researches indicated that a simple $\mathrm{CaCl}_{2}$ solution method could be used to screen $\mathrm{Al}$ tolerance for very young seedlings when the seed is still capable of providing all necessary mineral nutrients and avoid the problem of $\mathrm{Al}$ precipitation in Yoshida's solution (Famoso et al., 2010; Xia et al., 2010, 2013; Yokosho et al., 2011, 2016). Therefore, the simple $\mathrm{CaCl}_{2}$ solution method was applied in this study. After $48 \mathrm{~h}$, the seedlings for $\mathrm{Al}$ toxicity treatment were exposed to $0.5 \mathrm{mmol} \mathrm{l}^{-1}$ $\mathrm{CaCl}_{2}(\mathrm{pH}=4.0)$ containing 50,100,150, 200, 250, 300, 350, 400, 450, and $500 \mu \mathrm{mol} \mathrm{l}^{-1} \mathrm{AlCl}_{3}$ (no other nutrient solution was applied), while the seedlings for control were exposed to $0.5 \mathrm{mmol} \mathrm{l}^{-1} \mathrm{CaCl}_{2}(\mathrm{pH}=4.0)$ only. Then RRE was used to evaluate the degrees of $\mathrm{Al}$ tolerance of all varieties. RRE was calculated by following formula: $\mathrm{RRE}=$ root length under $\mathrm{Al}$ toxicity treatment/root length without $\mathrm{Al}$ toxicity treatment. The root length of 10 seedlings of each variety was measured with a ruler before and after the treatments $(24 \mathrm{~h})$ in one replicate, and six replications were performed. Then the most accurate $\mathrm{Al}^{3+}$ concentration for the detection of $\mathrm{Al}$ tolerance was selected, and that $\mathrm{Al}^{3+}$ concentration was further used to measure the $\mathrm{Al}$ tolerance of Ting' core collection.

All of rice seeds of the 150 varieties from Ting's core collection were harvested from the farm of South China Agricultural University, Guangzhou $\left(23^{\circ} 16 \mathrm{~N}, 113^{\circ} 8 \mathrm{E}\right)$, during the late season (July-November). Uniform seeds and seedlings were treated as aforementioned method with the determined $\mathrm{Al}^{3+}$ concentration from the previous step. Similarly, the root length of 10 seedlings of each accession was measured with a ruler before and after the treatment $(24 \mathrm{~h})$ in one replicate, and six replications were performed. Then the RRE value for each accessions of the Ting's core collection was calculated to measure $\mathrm{Al}$ tolerance. In the present study, RRE $\geq 0.5$ was used as a criterion to find out $\mathrm{Al}$ tolerant varieties (Fu et al., 2010).

\section{Genotyping}

A total of 274 SSR markers, evenly distributed across the 12 chromosomes of rice, were selected to genotype all varieties of Ting's core collection (Supplementary Table S2). A total of 23, 25, $24,22,21,22,21,25,23,24,23$, and 21 markers were mapped to chromosomes 1-12, respectively. The average distance between the loci in chromosomes 1-12 was 7.5, 8.2, 9.4, 7.4, 7.1, 6.3, 5.8, 5.4, 5.2, 4.7, 5.6, and $5.3 \mathrm{cM}$, respectively. Markers with prefix RM were selected from previously published data (Chen et al., 1997; Temnykh et al., 2000; McCouch et al., 2002), and those with prefix position-specific marker (PSM) were taken from the thesis of Huang (2003). DNA was extracted using a modified sodium dodecyl sulfate (SDS) method (Zheng et al., 1995). The volume of the polymerase chain reaction (PCR) was $10 \mu$ l. The profile of the PCR program was as follow: $94^{\circ} \mathrm{C}$ for 5 min followed by 29 cycles of $94^{\circ} \mathrm{C}$ for $1 \mathrm{~min}, 55^{\circ} \mathrm{C}$ for $1 \mathrm{~min}$, and $72^{\circ} \mathrm{C}$ for $1 \mathrm{~min}$ with a final extension of $5 \mathrm{~min}$ at $72^{\circ} \mathrm{C}$. PCR products were separated by electrophoresis on a $6 \%$ polyacrylamide gel and detected by silver staining (Panaud et al., 1996). A standard marker (100600 bp, produced by Shanghai Biocolor BioScience \& Technology Company) was added on each gel as a control. The size of PCR products were detected by BIO Imagine System with software Genetools from SynGene and were manually re-checked twice to reduce the errors (Zhang et al., 2011). The length of each allele was compared to the bands of the standard marker for scoring.

\section{Data Analysis}

Means and standard deviation (SD) for root length and RRE were calculated using Excel software. The percentage of phenotypic variation explained by population structure was calculated using a general linear model with software SPSS 17.0 for Windows (SPSS Inc. Chicago, IL, USA). The broad-sense heritability $\left(\mathrm{H}^{2}\right)$ was calculated as $\mathrm{H}^{2}=\sigma_{\mathrm{g}}^{2} /\left(\sigma_{\mathrm{g}}^{2}+\sigma_{\mathrm{e}}^{2}\right)$ using software QGA Station $1.0^{1}$, where $\sigma_{\mathrm{g}}^{2}$ is the genetic variance, and $\sigma_{\mathrm{e}}^{2}$ is the environmental variance. Polymorphism information content, which measures the extent of polymorphism for marker gene(s) or marker sequence(s), was calculated using the program POWERMARKER V3.25. Software Structure V2.3.1 was used to infer the population structure and to get Q matrices (Pritchard et al., 2000a,b). During the running, a range of genetic clusters from $\mathrm{K}=1-15$ with the admixture model was examined, and five replications were used for the estimation of each $\mathrm{K}$. Each run implemented with a burn-in period of 100,000 steps followed by 100,000 Monte Carlo Markov Chain replicates. An ad hoc measure $\Delta \mathrm{K}$ was used to detect the numbers of subgroups. That run with the maximum likelihood was applied to subdivide the varieties into different subgroups based on the maximum membership probability. A Q-matrix was obtained from the membership probability of each variety. The Q-matrix was used for further association mapping. The Loiselle algorithm was chosen for calculating the kinship matrix $(\mathrm{K})$ by software SPAGeDi (Hardy and Vekemans, 2002). Association analysis was performed using the software TASSEL ${ }^{2}$. For the mixed linear model (MLM), both $\mathrm{K}$ and $\mathrm{Q}$ matrices were incorporated. Significance of associations between marker and traits were determined by their $\mathrm{P}$ values $(\mathrm{P}<0.05)$, which were calculated by the statistical models, and the phenotypic variance explained by the significant loci was calculated through ANOVA. Rare alleles with the frequency of less than $10 \%$ in a population were filtered as missing data in association analysis. Quantile-quantile plots were generated for observed against expected $-\log _{10}(\mathrm{P})$ using software SAS version 9.0 (SAS Institute 2002), where observed P values were obtained from the association mapping and expected $\mathrm{P}$ values from the

\footnotetext{
${ }^{1}$ http://ibi.zju.edu.cn/software/qga/

${ }^{2}$ http://www.maizegenetics.net/tassel
} 
assumption that no associations happened between marker and trait.

\section{RESULTS}

\section{Determination of Al Toxicity Concentration}

There was no uniform concentration to measure the Al toxicity in previous studies. In this study, five rice varieties (control varieties, $\mathrm{CK}$ ) that have been reported as $\mathrm{Al}$ tolerant and sensitive were used to determine an appropriate concentration for Al toxicity or tolerance. The RRE of five CKs decreased with the increase in concentration of $\mathrm{Al}^{3+}$. When the $\mathrm{Al}^{3+}$ concentration was about $300 \mu \mathrm{moll}^{-1}$, the RRE reached a plateau and no further remarkable decline was found by increasing the $\mathrm{Al}^{3+}$ concentration. Furthermore, the RRE of five CKs decreased sharply when $\mathrm{Al}^{3+}$ concentration increased from 50 to $100 \mu \mathrm{mol} \mathrm{l}^{-1}$, and a maximum difference in RRE was observed at $100 \mu \mathrm{mol} \mathrm{l}^{-1}$ for the two tolerant and three sensitive CKs (Figure 1). Therefore, $100 \mu \mathrm{mol} \mathrm{l}^{-1}$ was determined as the most accurate concentration for $\mathrm{Al}$ toxicity.

\section{Identification of Al Tolerance Traits}

Ting's core collection showed a wide-range of phenotypic variation for $\mathrm{Al}$ tolerance, as indicated by the measurement of RRE, i.e., ranged from 0.22 to 0.89 with an average of 0.54 . Moreover, $63.70 \%$ of the 150 varieties had larger than 0.50 RRE (Figure 2). The variety with the largest RRE was a typical indica variety "Chang ning wu qu nan tou zhan," while the variety "Ai you" with the smallest RRE belong to typical japonica subspecies. The broad-sense heritability for Al tolerance was $88.73 \%$ (Table 1).

As $42.0 \%$ of phenotypic variation of $\mathrm{Al}$ tolerance was influenced by population structure (Table 1), it is necessary to compare the Al tolerance within subgroups and even subsubgroups of the core collection. In our previous study, three subgroups were presented in the Ting's core collection, i.e., SG 1 (indica), SG 2 (japonica), and AD (admixed) as well as four sub-subgroups were detected in the SG 1, including SG 1a (intermediate season landraces), SG 1b (subtropical landraces), SG 1c (late season landraces), and SG 1d (early season landraces) (Zhang et al., 2011).

In subgroup SG 1, RRE ranged from 0.22 to 0.77 with an average of 0.52 , and $52.78 \%$ of genotypes exhibited larger than 0.50 RRE. In subgroup SG 2, RRE ranged from 0.29 to 0.89 with an average of 0.59 , and $76.19 \%$ of landraces showed larger than 0.50 RRE. In AD, RRE ranged from 0.30 to 0.77 with an average of 0.57 , and $72.22 \%$ of RRE values were larger than 0.50 (Figure 3; Table 1). In sub-subgroup SG 1a, RRE ranged from 0.33 to 0.71 with an average of 0.54 , of these RRE values, $66.67 \%$ were larger than 0.50 . In sub-subgroup SG $1 \mathrm{~b}$, RRE ranged from 0.22 to 0.73 with an average of 0.46 , and only $29.41 \%$ of RRE values were larger than 0.50 . In sub-subgroup SG 1c, RRE ranged from 0.37 to 0.77 with an average of 0.54 , among them $47.62 \%$ of RRE displayed higher levels than 0.50. In sub-subgroup SG 1d, RRE ranged from 0.34 to 0.75 with an average of 0.55 , and $65.63 \%$ landraces displayed higher than 0.50 RRE (Figure 3; Table 1).

\section{The Effect of Controlling Type I Error Using MLM}

Observed versus expected $P$ values for each trait-marker association were plotted to assess the control of type I errors.

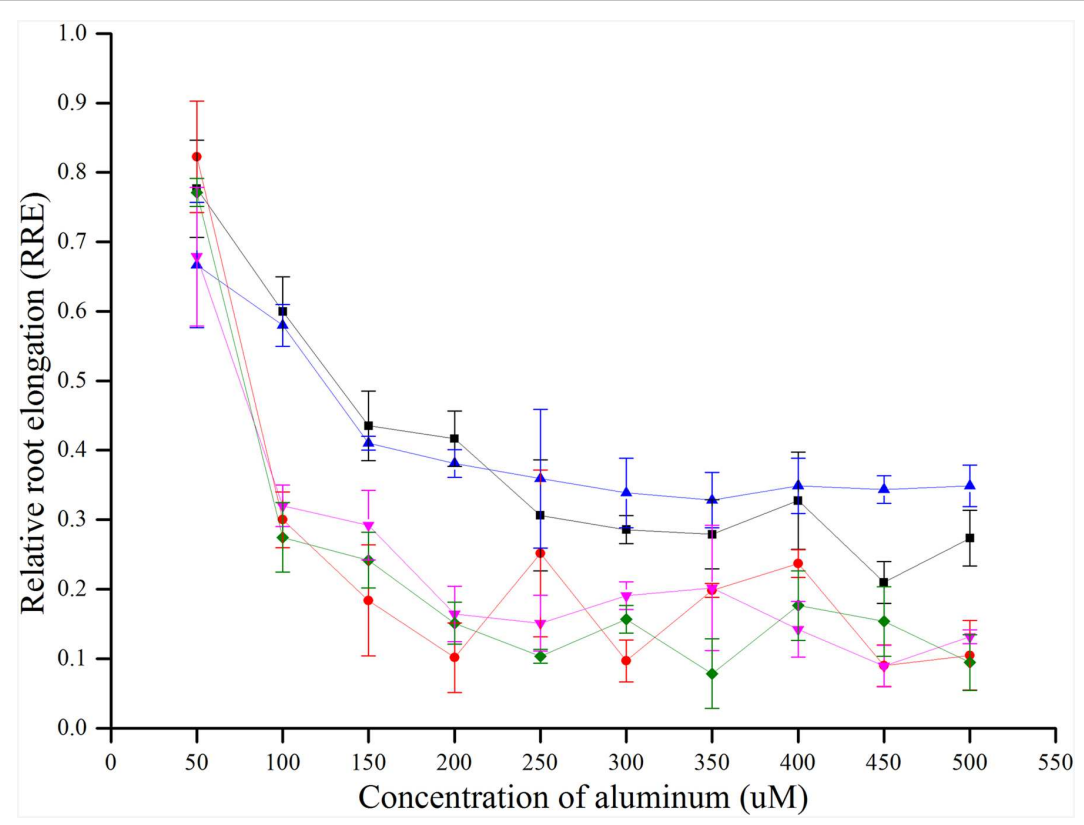

FIGURE 1 | RRE of five CKs (controls) treated with different concentrations of $\mathrm{Al}^{3+}$ for $24 \mathrm{~h}$. 


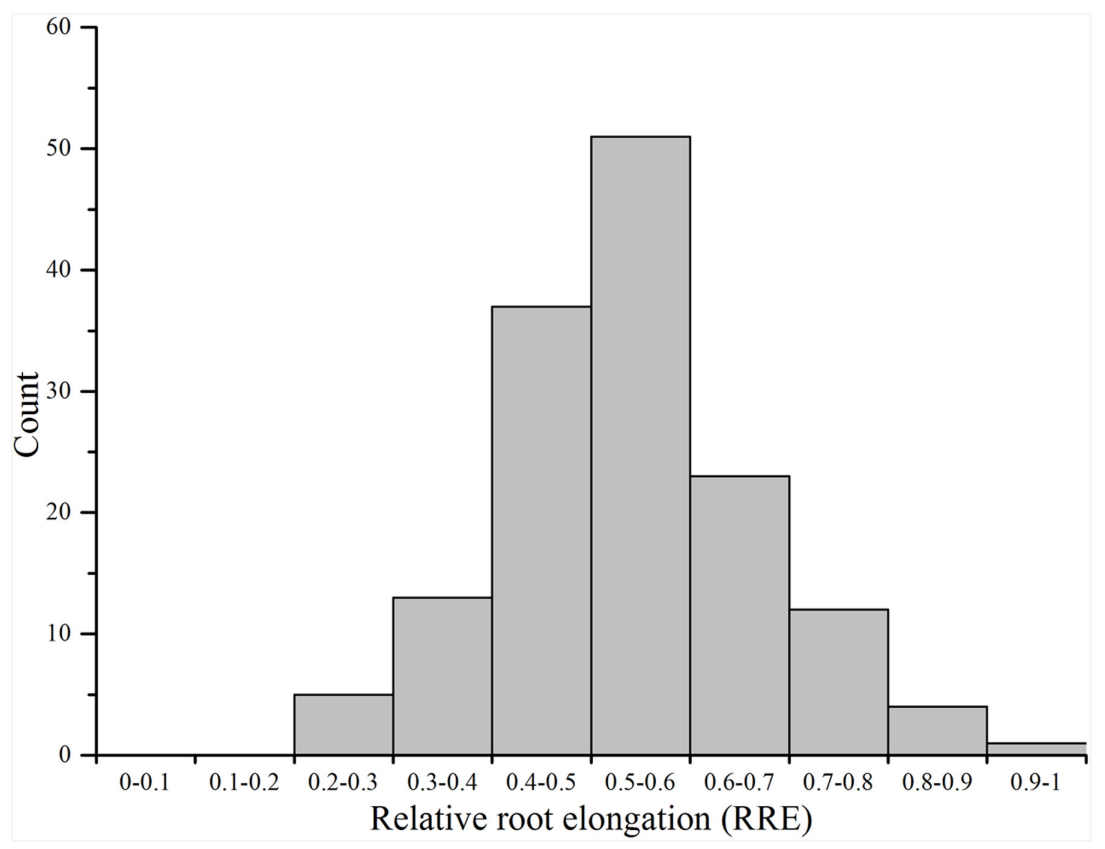

FIGURE 2 | Distribution of aluminum tolerance in the Ting's core collection.

TABLE 1 | Distribution of aluminum tolerance in the entire collection, subgroups, and sub-subgroups identified by STRUCTURE.



I, Indica; J, Japonica; ES, early season; LS, late season; IS, intermediate season; ST, subtropical. N is the sample size. $R^{2}$ and $h^{2}$ represent the percentage of phenotypic variation explained by population structure and heritability in broad sense, respectively.

Uniform distributions between the observed and expected $P$ values were observed for all the traits, and demonstrated by similar distributions in 2 years (Figure 4). The result indicated that MLM method effectively control the false positives in this study.

\section{Trait-Marker Associations for Al Tolerance}

A total of 23 trait-markers depicted significant associations $(P<0.05)$ with Al tolerance using MLM approach, and a total of $3,2,3,2,1,1,1,2,3,3,1$, and 1 trait-marker associations were mapped to chromosomes 1-12, respectively. Moreover, three $(13 \%)$ of 23 trait-marker associations for Al tolerance were identical to the previously reported QTLs (Table 2), and the other 20 trait-marker associations were new trait-marker associations for Al tolerance. The percentage of the phenotypic variation
$\left(R^{2}\right)$ explained by significant associations ranged from $5.03 \%$ (for RM341) to $20.03 \%$ (for PSM365), with an average of $11.65 \%$ (Table 2).

\section{Performance of Al Tolerance Relevant to Different Alleles of Significant Loci}

Six markers, i.e., PSM41, RM7, PSM377, RM252, PSM142, and PSM365, were selected for analysis of Al tolerance performance relevant to different alleles of significant loci based on their high explained phenotypic variation $(\geq 15 \%$, Table 2$)$. Six alleles, ranging from 140 to $180 \mathrm{bp}$, were detected at a locus PSM41 in Ting's core collection, and the individuals carrying the 180 bp allele (size of PCR product for the SSR markers), i.e., nine varieties including seven typical japonica and two indica varieties, had a significantly $(P<0.05)$ larger RRE than those carrying other alleles. Four alleles, ranging from 89 to 


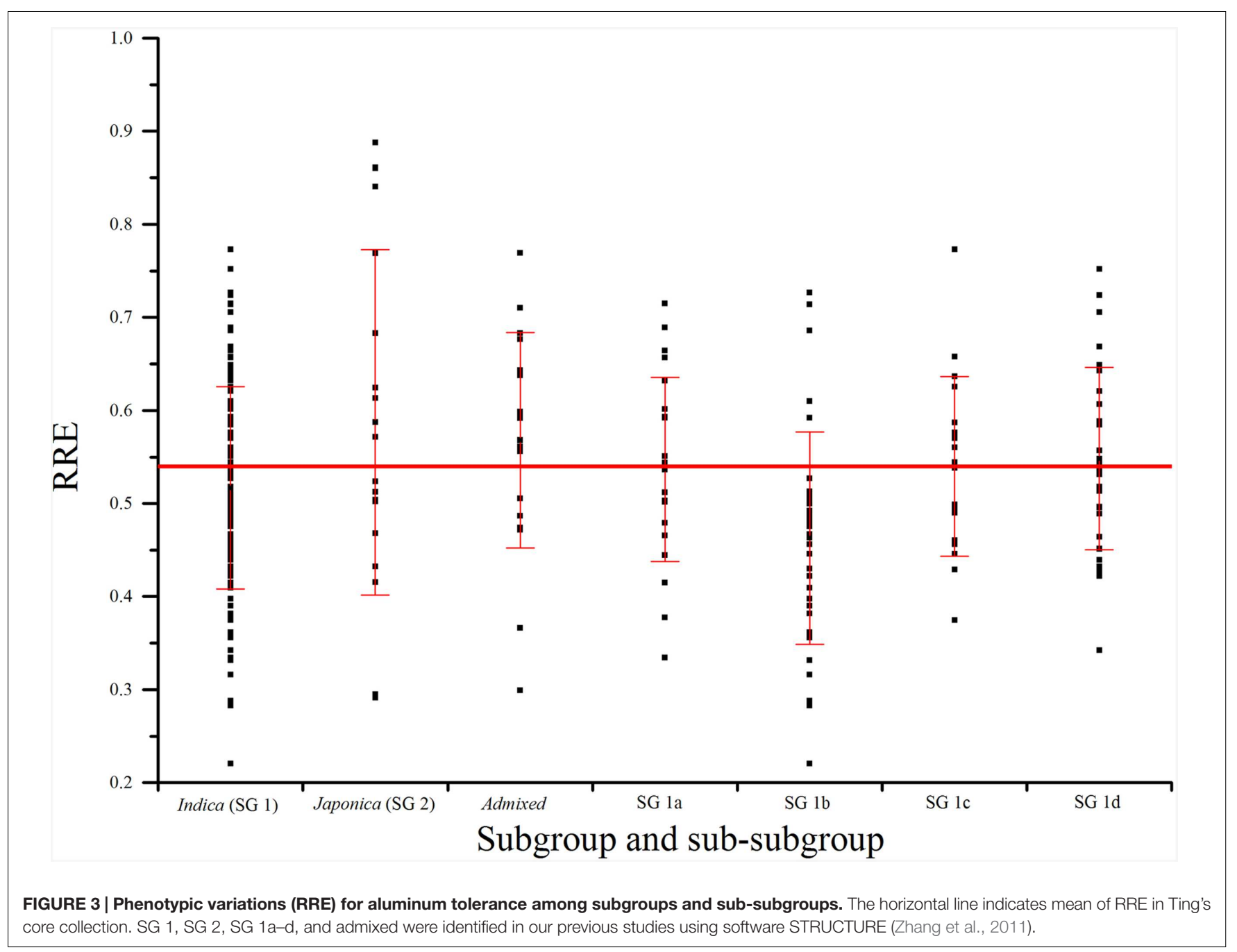

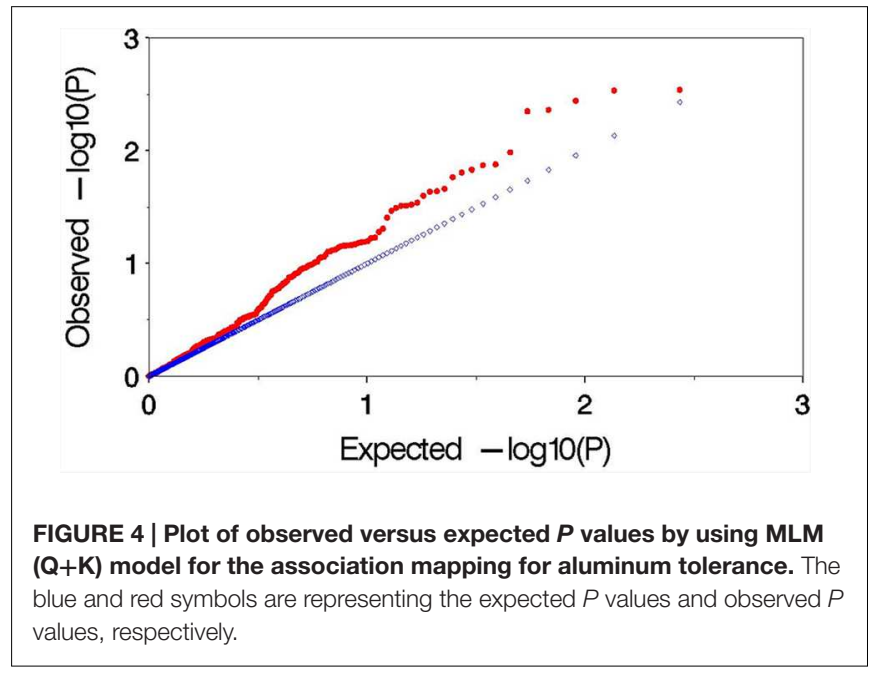

117 bp, were detected at a locus PSM377, and the individuals carrying the allele 93 bp, i.e., 26 varieties including 17 typical indica, five indica-clined and four typical japonica varieties, had a significantly $(P<0.05)$ larger RRE than those carrying $89 \mathrm{bp}$ allele. Five alleles, ranging from 163 to $201 \mathrm{bp}$ at a locus RM252, were detected, and the individuals carrying the allele of $201 \mathrm{bp}$ had a significantly $(P<0.05)$ smaller RRE than those carrying other alleles of 163,179 , and $198 \mathrm{bp}$. In addition, a total of four, six, and five alleles were detected in Ting's core collection with RM7, PSM365, and PSM142, respectively. However, we detected non-significant RRE index for the individuals relevant to different alleles of these loci (Table 3).

We found six varieties carrying 180 and 93 bp alleles at PSM41 and PSM377 loci, and eight varieties exhibited 179 and 93 bp alleles at RM252 and PSM377 loci, respectively (these accessions are shown in Supplementary Table S1). Moreover, the individuals carrying both 180 bp (PSM41) and 93 bp (PSM377) alleles had a larger RRE $(0.60 \pm 0.14)$ than those carrying only $93 \mathrm{bp}$ at PSM377 locus $(0.57 \pm 0.08)$. We detected larger RRE $(0.62 \pm 0.13)$ in the individuals harboring both 179 bp (RM252) and 93 bp (PSM377) alleles than those carrying a single allele, either 179 bp at locus RM252 (0.54 \pm 0.06$)$ or 93 bp at locus PSM377 $(0.57 \pm 0.08)$ (Supplementary Table S3). 
TABLE 2 | Significant $(P<0.05)$ associations between SSR markers and aluminum tolerance.

\begin{tabular}{|c|c|c|c|c|c|c|c|c|}
\hline No. & $\begin{array}{l}\text { Marker } \\
\text { names }\end{array}$ & $\begin{array}{l}\text { Chromosome } \\
\text { no. }\end{array}$ & Mb position & $P$-value (MLM) & $R^{2}(\%)$ & Candidate gene ID & Description & $\begin{array}{l}\text { Previous mapped } \\
\text { genes or QTLs }\end{array}$ \\
\hline 1 & PSM41 & 1 & 2.15 & 0.0044 & 16.59 & Os01g0140700 & $\begin{array}{l}\text { Regulator of the } \\
\text { ATPase of the vacuolar } \\
\text { membrane }\end{array}$ & None \\
\hline 2 & RM220 & 1 & 4.42 & 0.0146 & 6.3 & Os01g0183633 & $\begin{array}{l}\text { 60S ribosomal protein } \\
\text { L18a-like protein None }\end{array}$ & None \\
\hline 3 & RM306 & 1 & 15.66 & 0.0321 & 7.29 & None & $\begin{array}{l}\text { PAN domain-containing } \\
\text { protein At5g03700 }\end{array}$ & None \\
\hline 4 & RM341 & 2 & 19.34 & 0.0288 & 5.03 & Os02g0527900 & None & None \\
\hline 5 & PSM374 & 2 & 21.46 & 0.0043 & 11.79 & None & None & None \\
\hline 6 & RM7 & 3 & 9.83 & 0.0134 & 15.63 & None & Hypothetical protein & None \\
\hline 7 & PSM377 & 3 & 15.39 & 0.0299 & 15.07 & Os03g0386600 & $\begin{array}{l}40 S \text { ribosomal protein } \\
\text { S19 }\end{array}$ & CQL3 (Wu et al., 2000) \\
\hline 8 & RM156 & 3 & 17.71 & 0.017 & 6.02 & Os03g0424500 & None & None \\
\hline 9 & RM252 & 4 & 25.36 & 0.0029 & 15.33 & None & None & None \\
\hline 10 & RM559 & 4 & 35.33 & 0.0036 & 14.8 & None & None & None \\
\hline 11 & PSM341 & 5 & 0.66 & 0.0103 & 12.45 & None & $\begin{array}{l}\text { protein CURVATURE } \\
\text { THYLAKOID 1A, } \\
\text { chloroplastic None }\end{array}$ & None \\
\hline 12 & $\mathrm{RM} 136$ & 6 & 8.75 & 0.0339 & 12.94 & Os06g0264800 & $\begin{array}{l}\text { Alpha/beta hydrolase } \\
\text { fold-1 domain } \\
\text { containing protein }\end{array}$ & None \\
\hline 13 & PSM142 & 7 & 3.56 & 0.0307 & 18.39 & None & None & $\begin{array}{l}\text { QAIRr7.1 (Nguyen } \\
\text { et al., 2003) }\end{array}$ \\
\hline 14 & RM407 & 8 & 0.52 & 0.039 & 12.95 & Os08g0110000 & None & None \\
\hline 15 & RM339 & 8 & 17.94 & 0.0249 & 7.84 & None & None & None \\
\hline 16 & RM316 & 9 & 1.07 & 0.0227 & 12.29 & None & None & None \\
\hline 17 & RM342B & 9 & 8.55 & 0.0132 & 9.26 & None & None & None \\
\hline 18 & PSM340 & 9 & 21.67 & 0.0217 & 5.56 & None & None & None \\
\hline 19 & RM239 & 10 & 9.69 & 0.0229 & 12.18 & None & None & None \\
\hline 20 & PSM166 & 10 & 14.72 & 0.0306 & 9.48 & None & $\begin{array}{l}\text { Homeobox-leucine } \\
\text { zipper protein HOX9 }\end{array}$ & None \\
\hline 21 & RM258 & 10 & 18.08 & 0.0489 & 11.87 & Os10g0480200 & None & $\begin{array}{l}\text { qALRR-10 (Nguyen } \\
\text { et al., 2002) }\end{array}$ \\
\hline & & & & & & \multicolumn{2}{|c|}{ Hypothetical conserved gene } & \\
\hline 22 & PSM365 & 11 & 21.39 & 0.0029 & 20.03 & \multicolumn{2}{|l|}{ None } & None \\
\hline 23 & $\mathrm{RM} 179$ & 12 & 14.45 & 0.0156 & 8.89 & \multicolumn{2}{|l|}{ Os12g0438400 } & None \\
\hline
\end{tabular}

$R^{2} \%$ represents the percentage of phenotypic variance explained by the relevant marker.

\section{DISCUSSION}

Most of the previous studies on QTL mapping for Al tolerance were based on the selection of typical Al tolerant and sensitive rice accessions for constructing a segregating population and mapping. Different to previous studies, a core collection consisted of rice landraces was used for association mapping for $\mathrm{Al}$ tolerance in the present study. As rice landraces represent an intermediate stage in domestication between wild and elite cultivars (Londo et al., 2006), therefore, it contains high level of genetic diversity as well as potential elite genes for $\mathrm{Al}$ tolerance and other agronomic traits for genetic improvement of rice. The mapping population in this study, i.e., Ting' core collection, were collected from wide regions including the main rice growth countries in the very early stage (1920-1964). Moreover, the core collection was constructed based on 15 quantitative traits and 34 qualitative traits from 2262 accessions of rice landraces of Ting's collection with an optimal sampling strategy (Li et al., 2011). Consequently, screening for $\mathrm{Al}$ tolerance and mapping relevant QTLs within the core collection is of significant importance for the effective utilization of rice landraces.

\section{Selection of Al Toxicity Concentration}

There are several nutrient solutions which were used for rice Al tolerance screening. Among them, Yoshida's rice solution (Yoshida et al., 1976) is a classic one, which had been widely used to $\mathrm{Al}$ tolerance screening. However, high concentrations of mineral ions interacting with $\mathrm{Al}^{3+}$ in Yoshida's solution could obviously reduce the activity of $\mathrm{Al}^{3+}$ (Famoso et al., 2010). To avoid this, Famoso et al. (2010) modified the Magnavaca's nutrient solution by using Fe-hydroxyethylethylenediaminetriacetic acid (Fe-HEDTA) chelate to prevent $\mathrm{Fe}$ precipitation and citrate interaction with $\mathrm{Al}$, which could 
TABLE 3 | Duncan's test of the Al tolerant performance of rice landraces harboring different alleles of the markers significantly associated with AI tolerance.

\begin{tabular}{lccccc}
\hline Locus & $\begin{array}{c}\text { Allele } \\
(\mathbf{b p})\end{array}$ & Mean $\pm \mathbf{S} \boldsymbol{D}$ & Locus & $\begin{array}{c}\text { Allele } \\
(\mathbf{b p})\end{array}$ & Mean $\pm \mathbf{S D}$ \\
\hline PSM41 & 140 & $0.60 \pm 0.18^{\mathrm{ACab}}$ & PSM365 & 132 & $0.55 \pm 0.13^{\mathrm{Aa}}$ \\
& 145 & $0.51 \pm 0.14^{\mathrm{ABab}}$ & & 191 & $0.58 \pm 0.17^{\mathrm{Aa}}$ \\
& 152 & $0.53 \pm 0.12^{\mathrm{ABab}}$ & & 199 & $0.52 \pm 0.12^{\mathrm{Aa}}$ \\
& 167 & $0.54 \pm 0.10^{\mathrm{ABab}}$ & & 221 & $0.53 \pm 0.10^{\mathrm{Aa}}$ \\
& 177 & $0.46 \pm 0.12^{\mathrm{Ba}}$ & & 248 & $0.55 \pm 0.14^{\mathrm{Aa}}$ \\
& 180 & $0.65 \pm 0.13^{\mathrm{Cb}}$ & & 277 & $0.52 \pm 0.15^{\mathrm{Aa}}$ \\
$\mathrm{RM7}$ & 139 & $0.53 \pm 0.14^{\mathrm{Aa}}$ & PSM377 & 89 & $0.51 \pm 0.14^{\mathrm{Aa}}$ \\
& 152 & $0.53 \pm 0.11^{\mathrm{Aa}}$ & & 93 & $0.59 \pm 0.10^{\mathrm{Ba}}$ \\
& 155 & $0.55 \pm 0.14^{\mathrm{Aa}}$ & & 111 & $0.56 \pm 0.18^{\mathrm{ABa}}$ \\
& 160 & $0.55 \pm 0.12^{\mathrm{Aa}}$ & & 117 & $0.53 \pm 0.10^{\mathrm{ABa}}$ \\
$\mathrm{RM} 252$ & 163 & $0.55 \pm 0.15^{\mathrm{ABab}}$ & PSM142 & 147 & $0.52 \pm 0.10^{\mathrm{Aa}}$ \\
& 166 & $0.44 \pm 0.08^{\mathrm{ACab}}$ & & 156 & $0.50 \pm 0.12^{\mathrm{Aa}}$ \\
& 179 & $0.5 \pm 0.08^{\mathrm{Ba}}$ & & 168 & $0.56 \pm 0.16^{\mathrm{Aa}}$ \\
& 198 & $0.53 \pm 0.12^{\mathrm{ABab}}$ & & 179 & $0.57 \pm 0.13^{\mathrm{Aa}}$ \\
& 201 & $0.40 \pm 0.09^{\mathrm{Cb}}$ & & 184 & $0.53 \pm 0.14^{\mathrm{Aa}}$ \\
\hline
\end{tabular}

Upper and lower case letters represent significant differences at $\alpha=0.05$ and 0.01 , respectively.

greatly maintain the activity of $\mathrm{Al}^{3+}$ and can be used to screen Al tolerance in plants at all stages of development (Famoso et al., 2011). A simple $\mathrm{CaCl}_{2}$ solution method was also used to screen Al tolerance, especially for rice young seedlings, because at the early stage of development the seed is still capable of providing all necessary mineral nutrients (Ma et al., 2002). This method can effectively avoid the problem of $\mathrm{Al}$ precipitation and allows for reproducible $\mathrm{Al}^{3+}$ concentrations. Moreover, Xue et al. (2005) compared the two Al tolerance screening methods, i.e., the complete nutrient solution and the simple $\mathrm{CaCl}_{2}$ solution, to detect $\mathrm{Al}$ tolerance of two rice varieties Asominori (Al tolerant) and IR24 (Al sensitive) and found that the two screening methods showed non-significant difference. Therefore, as we used young seedlings to screen $\mathrm{Al}$ tolerance in this study, the simple $\mathrm{CaCl}_{2}$ solution method was applied.

In the previous studies, concentration for $\mathrm{Al}$ toxicity solutions was selected in a wide range due to different container, nutrient solution, treatment duration and other experimental factors. For instance, 20,30,160, and $160 \mu \mathrm{mol} \mathrm{l}^{-1}$ of $\mathrm{AlCl}_{3}$ were selected by Huang et al. (2009), Famoso et al. (2010), Xia et al. (2010), and Famoso et al. (2011), respectively. In this study, five tolerant and sensitive rice varieties were used to determine $100 \mu \mathrm{mol} \mathrm{l}^{-1}$ of $\mathrm{AlCl}_{3}$ as an appropriate concentration for Al toxicity. Similarly, $\mathrm{Fu}$ et al. (2010) found that the $100 \mu \mathrm{mol} \mathrm{l}{ }^{-1}$ of $\mathrm{AlCl}_{3}$ can differentiate between $\mathrm{Al}$ tolerant and sensitive varieties by using $\mathrm{RRE} \geq 0.5$ as a criterion for $\mathrm{Al}$ tolerant variety, and many rice varieties had been identified as tolerant or sensitive varieties using this criterion. This concentration was also used in the research of Xue et al. (2007), Zhang et al. (2007), and Cai et al. (2012). Therefore, the concentration for estimating the $\mathrm{Al}$ toxicity in this study, combined with RRE $\geq 0.5$ as Al tolerance level, is a reliable approach to measure the degree of $\mathrm{Al}$ tolerance in rice landraces.

\section{Performance of Al Tolerance in Ting's Core Collection}

As expected, our results indicated that there was a wide-range of phenotypic variation for $\mathrm{Al}$ tolerance in Ting's core collection. More than $63.70 \%$ varieties in Ting's core collection were found to be Al tolerant, which could be used as donor parents to introgress $\mathrm{Al}$ tolerance in elite rice varieties. We identified both indica and japonica rice varieties as $\mathrm{Al}$ tolerant varieties. Our results are in fully agreement with the Famoso et al. (2011), who also found $\mathrm{Al}$ tolerant varieties both in indica and japonica rice.

As $42.0 \%$ of phenotypic variation of $\mathrm{Al}$ tolerance was influenced by population structure, it is necessary to compare the $\mathrm{Al}$ tolerance within subgroups and even sub-subgroups. Both the percentage of Al tolerant varieties and mean of RRE in SG 2 were the largest (Figure 3; Table 2), which suggested that japonica might have more $\mathrm{Al}$ tolerant varieties than indica and admixed groups (mixture of indica and japonica). These findings were fully consistent with the study of Famoso et al. (2011). Moreover, the percentages of $\mathrm{Al}$ tolerant varieties and mean of RRE in $\mathrm{AD}$ were higher than other subgroups and sub-subgroups except SG 2 (Figure 3; Table 2), which might be attributed to the more number of japonica varieties in $\mathrm{AD}$ (four typical japonica rice, eight japonica-clined rice, and seven indica-clined rice). The percentage of $\mathrm{Al}$ tolerant varieties and mean of RRE in SG $1 \mathrm{~b}$ were the smallest, which suggested that the rice varieties from subtropical region are more sensitive to $\mathrm{Al}$ toxicity than other regions, and required the introgression of Al tolerance genes from other regions to produce resistance in these varieties.

\section{Association Analysis for Al Tolerance in Ting's Core Collection}

We used the MLM (Q+K; Yu et al., 2006) approach, which accounted for population structure and kinship relationship to minimize spurious associations, to perform association mapping for $\mathrm{Al}$ tolerance in Ting's core collection, which was genotyped by using 274 SSR markers. Our previous research indicated that LD decayed to $75 \%$ quantile of $r^{2}$ for unlinked loci at $40-50 \mathrm{cM}$ (Zhang et al., 2011), which was similar to the research of Jin et al. (2010) where LD did not decay until $25-50 \mathrm{cM}$ in a set of germplasm consisting of 416 rice accessions assessed with 100 SSR markers. Moreover, the LD blocks observed in our previous study had an average length of $7.1 \mathrm{cM}$, and the number of LD blocks for the core collection was 56. Therefore, though the number of SSR markers used in this study was low compared to the genome-wide high density single nucleotide polymorphisms (SNPs), association mapping with relative low number of markers is still possible. Such explanation could be supported by previous researches (e.g., Stich et al., 2008; Stich and Melchinger, 2009).

We detected significant $(P<0.05)$ trait-marker associations for Al tolerance on all rice chromosomes, while few rice chromosomes were found to harbor QTLs in previous studies. For instance, Famoso et al. (2011) detected a total of 3, 1, 1,1 , and 3 QTLs on chromosome 1, 2, 6, 9, and 12 by linkage mapping. Moreover, they cannot found any significant association on chromosome 8 by association mapping. We 
used a core collection of rice landraces, while two bi-parental segregation mapping populations and a rice panel consisting of 383 diverse rice accessions, which was not developed as a core collection, were used in the study of Famoso et al. (2011), thus different mapping populations might be the reason for different results in both studies. We detected about 13\% (three loci, Table 2) significant $(P<0.05)$ trait-marker associations identical to the QTLs reported previously, i.e., RM7 is located in the region of QTL CQL3 (Wu et al., 2000), PSM142 is located in the vicinity of QTL QAlRr7.1 (Nguyen et al., 2003), and RM258 was found to be in the region of QTL $q A L R R-10$ (Nguyen et al., 2002). The other significant associations found in this study, might be new novel loci for Al tolerance. For example, we detected nine significant associations located in the vicinity of candidate genes, i.e., PSM41 is located in the flanking region of $0 s 01 g 0140700$, which is a regulator of the ATPase of the vacuolar membrane; RM156 is located in the vicinity of $O s 03 g 0424500$, which encodes a $40 \mathrm{~S}$ ribosomal protein S193; RM136 is located in the region of Os06g0264800, which encodes a protein CURVATURE THYLAKOID 1A, chloroplastic; RM407 was found to be in the flanking region of Os08g0110000, which encodes an alpha/beta hydrolase fold-1 domain containing protein; RM258 is located in the region of Os10g0480200, which is similar to rolled leaf 1 and homeobox-leucine zipper protein HOX9; RM220, RM341, RM179, and PSM377 found to be in the regions of Os01g0183633, Os02g0527900, which have been annotated as protein(s) or gene(s) associated with important biological processes, respectively.

In addition, we found four loci that were located certain distance away from the regions containing genes or QTLs reported by previous studies. There was a $0.35 \mathrm{Mb}$ genetic distance between RM220 and OsCDT3 (encoding a plasma membrane-localized small peptide; Xia et al., 2013). PSM377 located at a distance of $3.8 \mathrm{cM}$ from CQL3 (Wu et al., 2000), while RM156 was located at a distance of $6.5 \mathrm{cM}$ from $q A L R R-3$ (Nguyen et al., 2002). RM407 and QA1Rr8.1 (Nguyen et al., 2003) was $3.4 \mathrm{cM}$ apart from each other. There is a possibility of QTLs DTH12 and Hd13 are being the same (detected in different mapping populations), though they have found a distance of $2.5 \mathrm{Mb}$ between two QTLs (Zhong et al., 2014). Further studies, especially map-based cloning and sequence analysis, are needed to confirm the linkage between these loci and previous QTL(s) or gene(s).

Based on our mapping results, the significant $(P<0.05)$ traitmarker associations with high $R^{2}$ deserve to study further. Our results indicated that the alleles with $180 \mathrm{bp}$ of PSM41, $179 \mathrm{bp}$ of

\section{REFERENCES}

Arenhart, R. A., Bai, Y., Valter, D. O. L., Bucker, N. L., Schunemann, M., Maraschin, F. D., et al. (2014). New insights into aluminum tolerance in rice: the ASR5 protein binds the STAR1 promoter and other aluminum-responsive genes. Mol. Plant 7, 709-721. doi: 10.1093/mp/sst160

Arenhart, R. A., Lima, J. C., Pedron, M., Carvalho, F. E., Silveira, J. A., Rosa, S. B., et al. (2013). Involvement of ASR genes in aluminium tolerance mechanisms in rice. Plant Cell Environ. 36, 52-67. doi: 10.1111/j.1365-3040.2012. 02553.x
RM252, and 93 bp of PSM377 might be the superior alleles for Al tolerance. Interestingly, $77.80 \%$ of the nine varieties harboring 180 bp allele at locus PSM41 were typical japonica, 96.00\% of the 25 varieties carrying 179 bp allele at locus RM252 were indica, and $80.80 \%$ of the 26 varieties containing 93 bp allele at locus PSM377 were indica. Both indica and japonica cultivars showed remarkable differences for $\mathrm{Al}$ tolerance mechanism during evolution (Famoso et al., 2011). Furthermore, the six varieties carrying the alleles of 180 and 93 bp as well as the eight varieties carrying the alleles of 179 and $93 \mathrm{bp}$ are worthy of further studies. These elite alleles for Al tolerance could be used for developing rice cultivars with $\mathrm{Al}$ tolerance through markerassisted breeding. Taken together, these results can be used as a reference for molecular breeding to improve $\mathrm{Al}$ tolerance in rice.

\section{AUTHOR CONTRIBUTIONS}

$\mathrm{PZ}$ and $\mathrm{JL}$ conceived and designed the experiments. $\mathrm{PZ}$ performed the experiments. PZ, JL, KZ, and HT analyzed the data. JL, PZ, and MS contributed reagents/materials/analysis tools. PZ, JL, KZ, and MS wrote and revised the manuscript.

\section{FUNDING}

This work was supported by the National Natural Science Foundation of China, grant 30700494, 31071842, and 31430062 and a fund in Zhejiang Province for public welfare (2016C32094).

\section{ACKNOWLEDGMENTS}

We are grateful to Academician Prof. Yonggne Lu for his novel guidance during the experiment, Dr. Dezhi Wu from Zhejiang University for helping us to revise our manuscript, Dr. Xiaoling Li, Dr. Lan Wang, Dr. Zhixiong Chen, Dr. Xuelin Fu, and Ms. Shuhong Yu from South China Agricultural University for their assistance.

\section{SUPPLEMENTARY MATERIAL}

The Supplementary Material for this article can be found online at: http://journal.frontiersin.org/article/10.3389/fpls.2016.01415

Arenhart, R. A., Schunemann, M., Bucker, N. L., Margis, R., Wang, Z. Y., and Margis-Pinheiro, M. (2016). Rice ASR1 and ASR5 are complementary transcription factors regulating aluminium responsive genes. Plant Cell Environ. 39, 645-651. doi: 10.1111/pce.12655

Cai, M., Zhang, S., Xing, C., Wang, F., Zhu, L., Wang, N., et al. (2012). Interaction between iron plaque and root border cells ameliorates aluminum toxicity of Oryza sativa differing in aluminum tolerance. Plant Soil 353, 155-167. doi: 10.1007/s11104-011-1019-0

Caniato, F. F., Hamblin, M. T., Guimaraes, C. T., Zhang, Z., Schaffert, R. E., Kochian, L. V., et al. (2014). Association mapping provides insights into the 
origin and the fine structure of the sorghum aluminum tolerance locus, AltSB. PLoS One 9:e87438. doi: 10.1371/journal.pone.0087438

Chen, X., Temnykh, S., Xu, Y., Cho, Y. G., and McCouch, S. R. (1997). Development of a microsatellite framework map providing genome-wide coverage in rice (Oryza sativa L.). Theor. Appl. Genet. 95, 553-567. doi: $10.1007 / \mathrm{s} 001220050596$

Chen, Z. C., Yamaji, N., Motoyama, R., Nagamura, Y., and Ma, J. F. (2012). Up-regulation of a magnesium transporter gene OsMGT1 is required for conferring aluminum tolerance in rice. Plant Physiol. 159, 1624-1633. doi: 10.1104/pp.112.199778

Delhaize, E., James, R. A., and Ryan, P. R. (2012a). Aluminium tolerance of root hairs underlies genotypic differences in rhizosheath size of wheat (Triticum aestivum) grown on acid soil. New Phytol. 195, 609-619. doi: 10.1111/j.14698137.2012.04183.x

Delhaize, E., Ma, J. F., and Ryan, P. R. (2012b). Transcriptional regulation of aluminium tolerance genes. Trends Plant Sci. 17, 341-348. doi: 10.1016/j.tplants.2012.02.008

Famoso, A. N., Clark, R. T., Shaff, J. E., Craft, E., McCouch, S. R., and Kochian, L. V. (2010). Development of a novel aluminum tolerance phenotyping platform used for comparisons of cereal aluminum tolerance and investigations into rice aluminum tolerance mechanisms. Plant Physiol. 153, 1678-1691. doi: 10.1104/pp.110.156794

Famoso, A. N., Zhao, K., Clark, R. T., Tung, C. W., Wright, M. H., Bustamante, C., et al. (2011). Genetic architecture of aluminum tolerance in rice (Oryza sativa) determined through genome-wide association analysis and QTL mapping. PLoS Genet. 7:e1002221. doi: 10.1371/journal.pgen.1002221

Flint-Garcia, S. A., Thornsberry, J. M., and Buckler, E. T. (2003). Structure of linkage disequilibrium in plants. Annu. Rev. Plant Biol. 54, 357-374. doi: 10.1146/annurev.arplant.54.031902.134907

Fu, X. L., Chen, W. D., Pan, C. H., Feng, J. H., Liu, X. D., and Lu, Y. G. (2010). A comparative study on aluminum tolerance between Oryza sativa and O.rufipogon in Gaozhou. Sci. Agric. Sin. 4, 661-669. doi: 10.3864/j.issn.05781752.2010.04.001

Fujii, M., Yokosho, K., Yamaji, N., Saisho, D., Yamane, M., Takahashi, H., et al. (2012). Acquisition of aluminium tolerance by modification of a single gene in barley. Nat. Commun. 3:713. doi: 10.1038/ncomms1726

Hardy, O. J., and Vekemans, X. (2002). SPAGEDi: a versatile computer program to analyse spatial genetic structure at the individual or population levels. Mol. Ecol. Notes 2, 618-620. doi: 10.1046/j.1471-8286.2002.00305.x

Huang, C. F. (2003). Development of Position-Specific Microsatellite Markers and Molecular Mapping of Insect Resistant Genes in Rice (Oryza sativa L.). M.Sc. thesis, South China Agricultural University, Guangzhou.

Huang, C. F., Yamaji, N., Chen, Z., and Ma, J. F. (2012). A tonoplast-localized halfsize $\mathrm{ABC}$ transporter is required for internal detoxification of aluminum in rice. Plant J. 69, 857-867. doi: 10.1111/j.1365-313X.2011.04837.x

Huang, C. F., Yamaji, N., Mitani, N., Yano, M., Nagamura, Y., and Ma, J. F. (2009). A bacterial-type $\mathrm{ABC}$ transporter is involved in aluminum tolerance in rice. Plant Cell 21, 655-667. doi: 10.1105/tpc.108.064543

Jin, L., Lu, Y., Xiao, P., Sun, M., Corke, H., and Bao, J. (2010). Genetic diversity and population structure of a diverse set of rice germplasm for association mapping. Theor. Appl. Genet. 121, 475-487. doi: 10.1007/s00122-010-1324-7

Khatiwada, S. P., Senadhira, D., Carpena, A. L., Zeigler, R. S., and Fernandez, P. G. (1996). Variability and genetics of tolerance for aluminum toxicity in rice (Oryza sativa L.). Theor. Appl. Genet. 93, 738-744. doi: 10.1007/BF00224070

Kochian, L. V., Hoekenga, O. A., and Pineros, M. A. (2004). How do crop plants tolerate acid soils? Mechanisms of aluminum tolerance and phosphorous efficiency. Annu. Rev. Plant Biol. 55, 459-493. doi: 10.1146/annurev.arplant.55.031903.141655

Kochian, L. V., Pineros, M. A., and Hoekenga, O. A. (2005). The physiology, genetics and molecular biology of plant aluminum resistance and toxicity. Plant Soil 4, 175-195. doi: 10.1093/jxb/erq272

Kraakman, A. T., Niks, R. E., Van den Berg, P. M., Stam, P., and Van Eeuwijk, F. A. (2004). Linkage disequilibrium mapping of yield and yield stability in modern spring barley cultivars. Genetics 168, 435-446. doi: 10.1534/genetics.104. 026831

Li, J. Q., and Zhang, P. (2012). "Assessment and utilization of the genetic diversity in rice," in Genetic Diversity in Plants, ed. M. Çalişkan (Rijeka: InTech-Open Access Publisher).
Li, J. Y., Liu, J., Dong, D., Jia, X., McCouch, S. R., and Kochian, L. V. (2014). Natural variation underlies alterations in Nramp aluminum transporter (NRAT1) expression and function that play a key role in rice aluminum tolerance. Proc. Natl. Acad. Sci. U.S.A. 111, 6503-6508. doi: 10.1073/pnas.1318975111

Li, X. L., Lu, Y. G., Li, J. Q., Xu, H. M., and Muhammad, Q. S. (2011). Strategies on sample size determination and qualitative and quantitative traits integration to construct core collection of rice (Oryza sativa). Rice Sci. 18, 46-55. doi: $10.1016 /$ S1672-6308(11)60007-3

Liu, J., Luo, X., Shaff, J., Liang, C., Jia, X., Li, Z., et al. (2012). A promoterswap strategy between the AtALMT and AtMATE genes increased Arabidopsis aluminum resistance and improved carbon-use efficiency for aluminum resistance. Plant J. 71, 327-337. doi: 10.1111/j.1365-313X.2012. 04994.x

Londo, J. P., Chiang, Y. C., Hung, K. H., Chiang, T. Y., and Schaal, B. A. (2006). Phylogeography of Asian wild rice, Oryza rufipogon, reveals multiple independent domestications of cultivated rice, Oryza sativa. Proc. Natl. Acad. Sci. U.S.A. 103, 9578-9583. doi: 10.1073/pnas. 0603152103

Ma, J. F., and Furukawa, J. (2003). Recent progress in the research of external Al detoxification in higher plants: a mini review. J. Inorg. Biochem. 97, 46-51. doi: 10.1016/S0162-0134(03)00245-9

Ma, J. F., Shen, R., Zhao, Z., Wissuwa, M., Takeuchi, Y., Ebitani, T., et al. (2002). Response of rice to $\mathrm{Al}$ stress and identification of quantitative trait Loci for $\mathrm{Al}$ tolerance. Plant Cell Physiol. 43, 652-659. doi: 10.1093/pcp/pcf081

Mao, C. Z., Yang, L., Zheng, B. S., Wu, Y. R., Liu, F. Y., Yi, K. K., et al. (2004). Comparative mapping of QTLs for Al tolerance in rice and identification of positional Al-induced genes. J. Zhejiang Univ. Sci. 5, 634-643. doi: 10.1631/jzus.2004.0634

McCouch, S. R., Teytelman, L., Xu, Y., Lobos, K. B., Clare, K., Walton, M., et al. (2002). Development and mapping of 2240 new SSR markers for rice (Oryza sativa L.). DNA Res. 9, 199-207. doi: 10.1093/dnares/9.6.199

Nguyen, B. D., Brar, D. S., Bui, B. C., Nguyen, T. V., Pham, L. N., and Nguyen, H. T. (2003). Identification and mapping of the QTL for aluminum tolerance introgressed from the new source, Oryza rufipogon Griff., into indica rice (Oryza sativa L.). Theor. Appl. Genet. 106, 583-593. doi: 10.1007/s00122-002-1072-4

Nguyen, V. T., Nguyen, B. D., Sarkarung, S., Martinez, C., Paterson, A. H., and Nguyen, H. T. (2002). Mapping of genes controlling aluminum tolerance in rice: comparison of different genetic backgrounds. Mol. Genet. Genomics 267, 772-780. doi: 10.1007/s00438-002-0686-1

Panaud, O., Chen, X., and McCouch, S. R. (1996). Development of microsatellite markers and characterization of simple sequence length polymorphism (SSLP) in rice (Oryza sativa L.). Mol. Gen. Genet. 252, 597-607. doi: 10.1007/BF02172406

Pilon-Smits, E. A., Quinn, C. F., Tapken, W., Malagoli, M., and Schiavon, M. (2009). Physiological functions of beneficial elements. Curr. Opin. Plant Biol. 12, 267-274. doi: 10.1016/j.pbi.2009.04.009

Pritchard, J. K., Stephens, M., and Donnelly, P. (2000a). Inference of population structure using multilocus genotype data. Genetics 155, 945-959.

Pritchard, J. K., Stephens, M., Rosenberg, N. A., and Donnelly, P. (2000b). Association mapping in structured populations. Am. J. Hum. Genet. 67, 170181. doi: $10.1086 / 302959$

Ryan, P. R., Tyerman, S. D., Sasaki, T., Furuichi, T., Yamamoto, Y., Zhang, W. H., et al. (2011). The identification of aluminium-resistance genes provides opportunities for enhancing crop production on acid soils. J. Exp. Bot. 62, 9-20. doi: $10.1093 /$ jxb/erq272

Stich, B., and Melchinger, E. (2009). Comparison of mixed-model approaches for association mapping in rapeseed, potato, sugar beet, maize, and Arabidopsis. BMC Genomics 10:94. doi: 10.1186/1471-2164-10-94

Stich, B., Piepho, H. P., Schulz, B., and Melchinger, A. E. (2008). Multi-trait association mapping in sugar beet (Beta vulgaris L.). Theor. Appl, Genet. 117, 947-954. doi: 10.1007/s00122-008-0834-Z

Temnykh, S., Park, W. D., Ayres, N., Cartinhour, S., Hauck, N., Lipovich, L., et al. (2000). Mapping and genome organization of microsatellite sequences in rice (Oryza sativa L.). Theor. Appl. Genet. 100, 697-712. doi: 10.1007/s001220051342

Vonuexkull, H. R., and Mutert, E. (1995). Global extent development and economic-impact of acid soils. Plant Soil 171, 1-15. doi: 10.1007/BF00009558

Wu, P., Liao, C. Y., Hu, B., Yi, K. K., Jin, W. Z., Ni, J. J., et al. (2000). QTLs and epistasis for aluminum tolerance in rice (Oryza sativa L.) at different seedling stages. Theor. Appl. Genet. 100, 1295-1303. doi: 10.1007/s001220051438 
Xia, J., Yamaji, N., Kasai, T., and Ma, J. F. (2010). Plasma membrane-localized transporter for aluminum in rice. Proc. Natl. Acad. Sci. U.S.A. 107, 1838118385. doi: 10.1073/pnas.1004949107

Xia, J., Yamaji, N., and Ma, J. F. (2013). A plasma membrane-localized small peptide is involved in rice aluminum tolerance. Plant J. 76, 345-355. doi: $10.1111 /$ tpj.12296

Xu, H. S., Gu, W. L., Dong, D. F., and Peng, X. X. (2004). Differential resistance of two subtropical rice cultivars to aluminum toxicity. J. Plant Nutr. 27, 1601-1609. doi: 10.1081/PLN-200026003

Xue, Y., Jiang, L., Su, N., Wang, J. K., Deng, P., Ma, J. F., et al. (2007). The genetic basic and fine-mapping of a stable quantitative-trait loci for aluminium tolerance in rice. Planta 227, 255-262. doi: 10.1007/s00425-007-0613-0

Xue, Y., Jiang, L., Zhang, W., Wang, C. M., Ma, J. F., Wan, J. M., et al. (2005). Mapping of quantitative trait loci associated with Aluminum tolerance in rice (Oryza sativa L.) using recombinant inbred lines. Acta Agron. Sin. 31, 560-564.

Yamaji, N., Huang, C. F., Nagao, S., Yano, M., Sato, Y., Nagamura, Y., et al. (2009). A zinc finger transcription factor ART1 regulates multiple genes implicated in aluminum tolerance in rice. Plant Cell 21, 3339-3349. doi: 10.1105/tpc.109.070771

Yan, J., Warburton, M., and Crouch, J. (2011). Association Mapping for Enhancing Maize (Zea mays L.) Genetic Improvement. Crop Sci. 51, 433-449. doi: 10.2135/cropsci2010.04.0233

Yang, Q., Wang, Y., Zhang, J., Shi, W., Qian, C., and Peng, X. (2007). Identification of aluminum-responsive proteins in rice roots by a proteomic approach: cysteine synthase as a key player in $\mathrm{Al}$ response. Proteomics 7, 737-749. doi: 10.1002/pmic.200600703

Yokosho, K., Yamaji, N., Kashino-Fujii, M., and Ma, J. F. (2016). Functional analysis of a MATE gene OsFRDL2 revealed its involvement in Al-induced secretion of citrate, but less contribution to Al tolerance in rice. Plant Cell Physiol. 57, 976-985. doi: 10.1093/pcp/pcw026

Yokosho, K., Yamaji, N., and Ma, J. F. (2011). An Al-inducible MATE gene is involved in external detoxification of $\mathrm{Al}$ in rice. Plant J. 68, 1061-1069. doi: 10.1111/j.1365-313X.2011.04757.x

Yoshida, S., Forno, D. A., Cock, J. A., and GomeZ, K. A. (1976). Laboratory Manual for Plant Physiological Studies of Rice, 3rd Edn. Manila: International Rice Research Institute.
Yu, J., Pressoir, G., Briggs, W. H., Vroh, B. I., Yamasaki, M., Doebley, J. F., et al. (2006). A unified mixed-model method for association mapping that accounts for multiple levels of relatedness. Nat. Genet. 38, 203-208. doi: 10.1038/ ng1702

Zhang, J., He, Z., Tian, H., Zhu, G., and Peng, X. (2007). Identification of aluminium-responsive genes in rice cultivars with different aluminium sensitivities. J. Exp. Bot. 58, 2269-2278. doi: 10.1093/jxb/erm110

Zhang, P., Li, J., Li, X., Liu, X., Zhao, X., and Lu, Y. (2011). Population structure and genetic diversity in a rice core collection (Oryza sativa L.) investigated with SSR markers. PLoS ONE 6:e27565. doi: 10.1371/journal.pone. 0027565

Zhang, P., Liu, X., Tong, H., Lu, Y., and Li, J. (2014). Association mapping for important agronomic traits in core collection of rice (Oryza sativa L.) with SSR Markers. PLoS ONE 9:e111508. doi: 10.1371/journal.pone.01 11508

Zheng, K., Qian, H., Shen, B., Zhuang, J., Lin, H., and Lu, J. (1995). PCR-based phylogenetic analysis of wide compatibility varieties in Oryza sativa L. Theor. Appl. Genet. 88, 65-69. doi: 10.1007/BF00222395

Zhong, Z., Wu, W., Wang, H., Chen, L., Liu, L., Wang, C., et al. (2014). Fine mapping of a minor-effect QTL, DTH12, controlling heading date in rice by upregulation of florigen genes under long-day conditions. Mol. Breed. 34, 311-322. doi: 10.1007/s11032-014-0035-1

Zhu, C. S., Gore, M., Buckler, E. S., and Yu, J. M. (2008). Status and prospects of association mapping in plants. Plant Genome 1, 5-20. doi: 10.3835/plantgenome2008.02.0089

Conflict of Interest Statement: The authors declare that the research was conducted in the absence of any commercial or financial relationships that could be construed as a potential conflict of interest.

Copyright (c) 2016 Zhang, Zhong, Tong, Shahid and Li. This is an open-access article distributed under the terms of the Creative Commons Attribution License (CC BY). The use, distribution or reproduction in other forums is permitted, provided the original author(s) or licensor are credited and that the original publication in this journal is cited, in accordance with accepted academic practice. No use, distribution or reproduction is permitted which does not comply with these terms. 